\title{
MUSIC-haic : 3D MUltidisciplinary tools for the Simulation of In-flight iCing due to High Altitude Ice Crystals
}

\author{
Philippe Villedieu and Pierre Trontin ONERA \\ Gilles Aouizerate SAFRAN Aircraft Engines \\ Stephan Bansmer Technische Universität Braunschweig \\ Paolo Vanacore General Electric Aviation \\ Ilia Roisman and Cameron Tropea Darmstadt University of Technology
}

\begin{abstract}
Icing is a major hazard for aviation safety. Over the last decades an additional risk has been identified when flying in clouds with high concentrations of ice-crystals where ice accretion may occur on warm parts of the engine core, resulting in engine incidents such as loss of engine thrust, strong vibrations, blade damage, or even the inability to restart engines. Performing physical engine tests in icing wind tunnels is extremely challenging, therefore, the need for numerical simulation tools able to accurately predict ICI (Ice Crystal Icing) is urgent and paramount for the aeronautics industry, especially regarding the development of new generation engines (UHBR = Ultra High Bypass Ratio, $\mathrm{CROR}=$ Counter rotating Open Rotor, ATP $=$ Advanced Turboprop) for which analysis methods largely based on previous engines experience may be less and less applicable. The European research project MUSIC-haic has been conceived to fill this gap and has started in September 2018. MUSIC-haic brings together the main European research institutions working on icing modelling as well as engine manufacturers and aircraft manufacturers. The project will develop advanced ice crystal icing models, implement them in existing industrial 3D multi-disciplinary tools, and finally perform extensive validation of the new ICI numerical capability through comparison of numerical results with both academic and industrial experimental data. The aim of the present paper is to provide an overview of the project technical objectives, scientific ambition and methodology, and work breakdown structure.
\end{abstract}

\section{Introduction}

When flying in clouds with high concentrations of ice-crystals (ranging in size from $50 \mu \mathrm{m}$ to $500 \mu \mathrm{m}$ ) or with mixed phase conditions (i.e. ice crystals combined with supercooled water droplets), ice accretion may occur on warm parts of the engine compressor (see Figure 1), resulting in sudden loss of engine thrust, engine flame-out, and even irreversible damage leading to a strong risk of permanent power loss and of being unable to restart the engine. An Engine Harmonization Working Group study published in 2009 [1] identified 140 engine power loss events due to engine core icing since the early 1980's. Newer aircraft are also affected, as demonstrated by events on recent aircraft and engine types [2]. Pitot probes are also likely to be affected, as the exposed heated tube acts as a particle collector, which may lead to probe inlet obstruction if heating is not sufficient to melt the ice, or if the water cannot be fully evacuated in case of severe icing conditions.
This hazard and its potential operational consequences for aircraft fleets and engine operability led to define new certification rules for aircraft. The FAA proposed new certification requirements for flying in ice-crystal icing conditions (CFR - title 14 - part 33.68 and AC 20147A). In Europe, work on ICI conditions was included in the European Aviation Safety plan and this resulted in the issuing of new certification specifications in March 2015 (CS-E Amendment 4 and CS25-Appendix P) which are henceforth applicable for all new products. In view of the pending applicability of these changes, aircraft and engine manufacturers created two international working groups: the Engine Icing Working Group (EIWG) to support the aviation authorities on rulemaking, and the Ice Crystals Consortium (ICC) to investigate the physics of ice crystals into jet engines.

Ice crystal icing (ICI) is thus a safety concern that has become paramount for the aeronautic industry over the last decade and which is extremely difficult to address through ground-testing and currently not completely addressable with numerical tools. However, being capable of predicting ICI is key for both design and certification, since today's analysis methods, largely based on previous engines experience, may be less and less applicable to next generation of products exploiting breakthrough architectures. This is likely for greener fuel efficient engines with very high bypass ratios which may be even more susceptible to ICI than currently in-service turbofan. Similarly, the next generation of air data probes will have to be more accurate and energy efficient and so will be more sensitive to icing threats.

Given the size of commercial aircraft engines and the need to be able to reproduce representative in-flight conditions (ice crystal concentration, ice crystal size distribution, flight altitude, speed and temperature) the ability to perform physical engine tests in icing wind tunnels (IWT) is extremely challenging, expensive and currently limited to partial tests for engine components. This is because available facilities are too small to accommodate ever-growing engine diameters. Moreover, the ability to mimic glaciated and mixed phase conditions in icing wind tunnels is still being developed and is not yet fully available in all facilities, especially the largest ones. Another difficulty arises when examining the icing of air data probes positioned on the fuselage of aircraft. Although ICI tests are now possible in small IWTs, the difficulty in probe certification remains the ability to reproduce a realistic concentration of ice crystals impacting the probe. The position of the probe on the airframe has a strong influence on the ice crystal concentration in its vicinity, which can often be much higher than the average concentration within the cloud. 
Therefore, the availability of numerical simulation tools capable of accurately predicting ice crystal icing (ICI) is an urgent and paramount need for the aeronautics industry to support the development and certification of new aircraft. This requires going beyond the progress made over the last five years in North America and in Europe, in particular in the framework of the HAIC FP7 EU project (2012-2016) [28], where the development of appropriate numerical tools was initiated. The project made significant progress, but there are still several important gaps, which prevent current numerical tools from being used by the industry:

- Certain microphysics models (in particular related to ice crystal sticking, fragmentation, accretion, and shedding) are not sufficiently mature. Complementary experimental data are required to improve or reformulate these models and to extend their validity and validation level,

- With some exceptions, the models developed in HAIC have only been integrated into 2D codes which are an essential milestone on the route to the development of 3D tools, but which have a limited use for industrial purposes, especially in the context of ICI, where the main exposed aircraft components are engines and probes, both exhibiting complex 3D geometries and involving highly $3 \mathrm{D}$ flows,

- Code validation has to date been limited to comparisons with academic experimental results using simple 2D geometries (accretion on an airfoil or on a cylinder positioned in an icing wind tunnel). Since 3D tools with a full ICI capability are not available yet, only few feasibility tests on actual engine or aircraft nose configurations have been performed rather than real validation tests.

Thus, to fill these gaps, the European research project MUSIC-haic has been launched in September 2018. This is a four-year project which brings together the main European research institutions working on icing modelling (ONERA, CIRA, TsAGI, Technische Universität Darmstadt (TUDA), Technische Universität Braunschweig (TUBS), Airbus Central Research Entity), as well as engine manufacturers (SAFRAN Aircraft Engines, Rolls-Royce, General Electric) and aircraft manufacturers (Airbus and Dassault-Aviation). Its objectives are to update, improve or replace the existing ICI models, to incorporate them in currently used industrial 3D multi-disciplinary tools and to validate the new resulting ICI capability for both design and certification of new engines, probes and aircraft. This paper presents the technical objectives of the project, its scientific ambition and methodology and finally its work breakdown structure.

\section{Concept and Methodology of MUSIC-haic}

\section{Physical scenario for ICI}

Ice accretion in glaciated icing conditions involves complex coupled physical phenomena which are very different from that of supercooled droplet icing, since frozen ice crystals bounce off cold surfaces; hence, airframe icing is often not noticed during aircraft operation in high altitude ice crystal clouds. For observing ice growth on a surface due to ice crystals, a certain amount of liquid water has to be present in order to allow ice particles to stick (at least partially) to the wall. This condition is obviously met in mixed phase clouds but also in high altitude glaciated clouds, given that the accretion site flow environment or the surface itself, is warm enough for initially fully frozen particles to melt. This is typically the case in turbofan engines and heated probes. The physical scenario of ICI is now quite well understood [24,25]. It is as follows:
- the warm airflow inside the engine/probe melts (or at least partially melts) the ice crystals which are quite small, typically having a diameter between a few tens and a few hundreds of micrometers;

- when melting ice particles - or a mixture of droplets and ice crystals in mixed phase clouds - enter the system and impact a surface, they may stick to the wall and can form a liquid film (when the wall is warm enough to melt all the ice) or a mixture of liquid water and ice particles on the surface;

- alternatively, ice particles impacting onto the surface may fragment, and resulting small fragments may re-impact and partially melt on the warm surface $[12,34]$;

- new incoming ice particles are captured in the liquid wall film or in the mixed phase accreted layer and heat transfer with the wall takes place; heat is extracted from the surface until the freezing point is reached, and ice begins to form, forming a strong adhesion layer to the wall, the adhesion strength depending (at least) on the amount of liquid water which is present in the accreted layer.

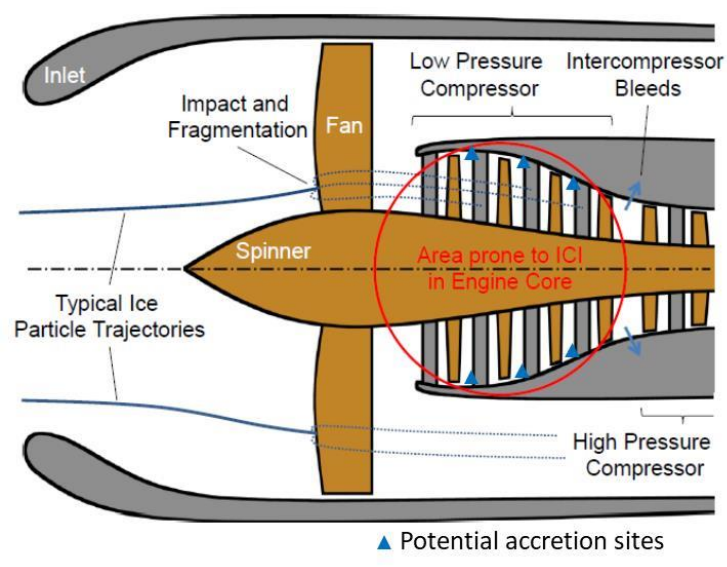

Figure 1: Sketch of typical turbofan engine.

(Typical trajectories of ice particles are shown. Inlet, fan, and spinner are illustrated where fully frozen ice particles may impact and fragment. Ice particles entering the engine core may melt and accrete on surfaces of the low pressure compressor, whereas ice particles in the bypass airflow are non-hazardous)

As far as turbofan engines are concerned, the residence time in the potential accretion sites is very small and the ice crystals must be small enough for the melting process to occur. In practice, this condition is fulfilled due to the impact of ice crystals on engine walls (spinner, fan blades, etc.) before entering the low pressure compressor core. These impacts lead to the creation of small ice fragments (a few tens of $\mu \mathrm{m}$ ) having a much lower thermal inertia than the original crystals. Concerning probes, the influence of impacts and secondary particle reemission is also of major importance since they may strongly affect the ice crystal concentration in the vicinity of a probe. Depending on the probe location on the aircraft, the local ice crystal concentration may be much higher than in the cloud; this effect is called "probe installation effect".

\section{ICI numerical capability main requirements}

Having in mind this scenario, an ICI numerical capability must therefore satisfy the following four conditions to be used by industry for both design and certification purposes: 
$\checkmark \quad$ it must be a part of a multi-disciplinary tool to deal with the multi-physics nature of ICI,

$\checkmark$ it must be part of a three-dimensional tool since twodimensional simulations are rarely applicable to engines and probes, which are the most critical aircraft components with respect to ICI,

$\checkmark \quad$ it must rely on a comprehensive set of ice crystal physical models (for drag, melting, wall interactions, accretion, etc.) to be able to reproduce all the complex physical phenomena which are simultaneously at play,

$\checkmark$ it must be validated for representative industrial configurations by comparing numerical and experimental results for realistic engine and probe tests cases based on wind tunnel and flight tests.

Such numerical tools would be structured according to the schematic diagram depicted in Figure 2. This structure requires coupling between separate solvers, each one being dedicated to a given physics: aerothermodynamics, particle trajectory and impact, accretion, and heat conduction.

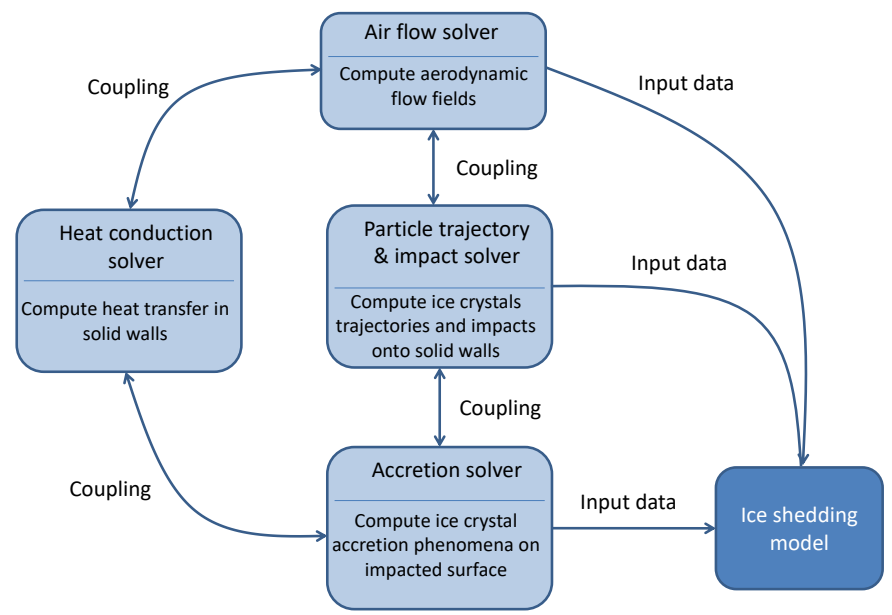

Figure 2: Schematic of a typical 3D multi-disciplinary tool applied to ICI simulation

\section{Existing building blocks}

To develop the new 3D ICI numerical capability, MUSIC-haic will not start from scratch, but will benefit from many important existing building blocks that are briefly described below.

Physical models - HAIC sub-project 6, which was devoted to models and tools development, made significant progress in the understanding of physical phenomena controlling ice crystal icing and led to the creation of a first generation of ICI models. All these models were implemented in 2D numerical research tools [13,16,21,22,26,29,32] for the purpose of empirical constant calibration and first level validation (i.e. based on academic configurations that are well-instrumented but only partially representative of real industrial applications).

ICI physics experimental database - To support the development of ICI models, extensive experimental activities were performed within the HAIC project by TUDA, AGI, TUBS and TSAGI and in parallel, in the scope of North American projects, by the CNRC and NASA (the results of which have largely been made public at recent AIAA and SAE conferences). These complementary experimental investigations allowed a large database to be created (which is hereafter referred to as ICI physics database) [4,5,6,7,8,11,12,13,14,17,18,20,30,31]. More Page 3 of 10 details of the content of the existing ICI physics database will be provided bellow.

ICI industrial database - HAIC-HIWC flight tests permitted the characterization of high altitude ice crystals properties and the collection of data for quantifying probe installation effects. Within the HAIC project, ICI tests with a Pitot probe were performed in the French DGA icing wind tunnel. In parallel, full engine tests (with a Honeywell ALF 502 turbofan engine) were performed in NASA's large IWT (Propulsion Systems Laboratory - PSL) [9,10]. All these experiments led to the creation of a second database (which is hereafter referred to as the ICI industrial database), being less detailed than the ICI physics database, but which is representative of targeted applications and real operating conditions.

\section{A TRL approach to drive the project and prepare future exploitation.}

A Technology Readiness Level (TRL) approach will be followed to drive the project, ensuring a close monitoring of the development and validation steps and preparing tool exploitation by industry. The existing models that were developed in previous research projects, and especially in the scope of HAIC, are currently between TRL2 and TRL4, the most advanced ones being those dedicated to ice crystal trajectory phenomena (dynamics, heat exchange and phase change phenomena), the less advanced ones being those dedicated to shedding phenomena.

Table 1: Criteria for the evaluation of TRL pass in MUSIC-haic

\begin{tabular}{|l|l|l|}
\hline TRL & EC Annexe G & $\begin{array}{l}\text { MUSIC-haic } \\
\text { scale/criteria }\end{array}$ \\
\hline TRL2 & $\begin{array}{l}\text { Technology } \\
\text { concept } \\
\text { formulated }\end{array}$ & $\begin{array}{l}\text { Underlying physical } \\
\text { phenomena understood }\end{array}$ \\
\hline TRL3 & $\begin{array}{l}\text { Experimental } \\
\text { proof of concept }\end{array}$ & $\begin{array}{l}\text { Model equations } \\
\text { established / basic tests } \\
\text { performed }\end{array}$ \\
\hline TRL4 & $\begin{array}{l}\text { Model integrated in } \\
\text { research tools (2D). } \\
\text { Validation tests } \\
\text { successfully performed } \\
\text { against academic } \\
\text { experiments. }\end{array}$ \\
\hline TRL5 & $\begin{array}{l}\text { Model integrated in } \\
\text { industrial tools (3D). } \\
\text { Validation tests } \\
\text { successfully performed } \\
\text { Technology } \\
\text { validated in } \\
\text { relevant } \\
\text { environment }\end{array}$ & $\begin{array}{l}\text { against academic } \\
\text { experiments and } \\
\text { feasibility checked for } \\
\text { realistic applications. }\end{array}$ \\
& $\begin{array}{l}\text { Validation against } \\
\text { representative industrial } \\
\text { applications successfully } \\
\text { performed and best } \\
\text { practices formulated. }\end{array}$ \\
\hline TRL6 & $\begin{array}{l}\text { Technology } \\
\text { demonstrated in } \\
\text { relevant } \\
\text { environment }\end{array}$ & \\
\hline
\end{tabular}


MUSIC-haic will complete the development of these models, implement them in existing 3D multi-disciplinary tools and perform extensive validations. The overall objective is to provide industry with an ICI numerical capability that has been brought up to TRL6. To reach this goal, four TRL reviews will be planned: a TRL3/4 review at Month 24 (M24), TRL4 review at Month 30 (M30), TRL5 at Month 40 (M40) and TRL6 at Month 47 (M47). The criteria for the evaluation of TRL pass are given in Table 1.

\section{MUSIC-haic Methodology}

Initially, new experiments will be performed to provide the modellers with missing data for improving and recalibrating models. Building on these and existing data, the development of a comprehensive set of models for ice crystal impact (including erosion effects and sticking efficiency), ice accretion and shedding phenomena will be completed. For each physical phenomenon, the approach used will be:

- Identification of the principal parameters by thoroughly analysing the available experimental data and the existing theoretical knowledge in related fields.

- Construction of theoretical or semi-empirical models involving only dimensionless numbers built upon the principal parameters.

- Calibration of the constants of these models by using the available experimental data. This will be performed by comparing experimental results of simple and well instrumented cases to $2 \mathrm{D}$ numerical simulations.

The models will first be implemented in existing 2D icing codes to perform the calibration and validation. The most promising candidates for implementation in 3D tools will be identified through numerical benchmarking by comparing results of the different partners, using identical test cases based on the ICI physics database.

Having first precisely defined the required specifications for the 3D tools, the existing 3D multi-disciplinary tools will be prepared for the integration of the ICI models. In particular, the missing couplings between internal solvers or between internal and external solvers will be implemented.

Finally, the down-selected ICI models will be integrated into the corresponding solvers and will be preliminary tested, to ensure that the updated 3D tools are ready to run for the final assessment based on the industrial database. Relevant test cases for design and certification (some of them being common, others being private) will be defined and run by the research centres and the industrial partners. The test cases will be based on the existing industrial database already mentioned above. Result analysis and conclusions will be shared, common best practices will be defined and eventual needs for future research will be identified.

\section{Scientific ambition of MUSIC-haic}

As outlined previoulsy, ice accretion under glaciated icing conditions involves complex physical phenomena which are very different from that of supercooled droplet icing. To be able to perform reliable numerical simulations of ICI, a set of dedicated models has first to be developed and implemented in existing 3D multi-disciplinary tools. These models must account for all the following complex physical phenomena and their couplings:

- the aerodynamic force acting on ice crystals (which are nonspherical particles) carried by an air flow,

Page 4 of 10
- heat and mass exchange with the surrounding air flow and (partial) melting process along ice crystal trajectories,

- the impact of ice crystals on a solid surface (impact regimes thresholds, secondary particle fragment characteristics, sticking efficiency, erosion phenomena i.e. accretion abrasion by particle impact ...),

- the accretion of ice crystals on a solid surface by taking into account heat and mass exchange with the solid substrate and the air flow, as well phase change and transport phenomena in the accreted ice-water layer,

- the shedding of ice pieces due to the combined effects of aerodynamic forces at the ice - air interface and melting phenomena at the ice - wall interface.

The objective of MUSIC-haic is to go well beyond the current state of the art by achieving major progress in the understanding and in the modelling of all these physical phenomena, and by providing industry with validated $3 \mathrm{D}$ multi-disciplinary tools for ICI simulations. The following paragraphs present the state of the art, the remaining gaps and the progress and main achievements which are expected from MUSIC-haic.

\section{Advanced experimental investigations to complement existing data for supporting ICI models development and validation}

State of the art and main limitations. Due to the high complexity of ICI physics, development of purely theoretical models is not realistically feasible. For each of the above listed physical phenomena, a model must necessarily contain at the end a certain element of empiricism. It is therefore mandatory to perform experiments to understand the main physical mechanisms which are at play, to identify the most influential parameters, and to acquire a set of data that will be used by the modellers for model development, calibration and validation. This is the scientific program that has been followed in Europe within the HAIC project and in parallel by NASA and CNRC in the scope of North American research projects. Many complementary experiments have been carried out to study all the above mentioned physical phenomena. In Europe:

- TUDA (Technische Universität Darmstadt) performed two laboratory experiments to investigate the influence of ice crystal shape on their dynamics and to measure the drag coefficient of nonspherical particles of different shapes and different Reynolds numbers [35].

- Ice particle melting experiments in a controlled airflow were also conducted by Airbus Central Research Entity in Munich using an acoustic levitator for the suspension of individual spherical and nonspherical ice particles $[11,13,14]$.

- Experiments to study single ice particle impact onto a flat rigid target (see Figure 3) were conducted within the Airbus iCORE facility $[11,12,19]$.

- Using generic test articles (cylinder, 2D airfoil), TUBS (Technische Universität Braunschweig) and TSAGI performed parametric ice accretion studies in their IWT to observe and quantify the influence of some critical parameters on the accretion growth rate and final shape such as the airflow velocity, the airflow temperature, the melt ratio, the leading-edge wall temperature, etc [3]. The TsAGI and TUBS IWT, not being able to reproduce warm airflow environment (to melt fully glaciated ice crystals), focused the accretion experiments on mixed-phase ICI conditions.

At the CNRC Research Altitude Test Facility (RATFac), a series of experiments were performed to investigate the influence of 
aerothermal and icing cloud conditions on the accretion growth rate and erosion rate $[4,5,6,7,8,17,18,20]$. CNRC used generic test articles (wedge airfoil, hemispherical surface, crowned cylinder) and focused most of their investigations on the case of glaciated icing conditions combined with a warm air environment (air flow temperature above freezing) to be as close as possible to the real encountered conditions in engines. In all experiments, significant ice accretion was observed for melting ratios ranging from 5 to 35 percent (depending on the aerothermal conditions), with a plateau of almost constant icing severity, which drastically decreases at its left and right limits (see Figure 4). The CNRC experiments have also shown that the plateau narrows for increased crystal speeds and sizes because of increased erosion effects.

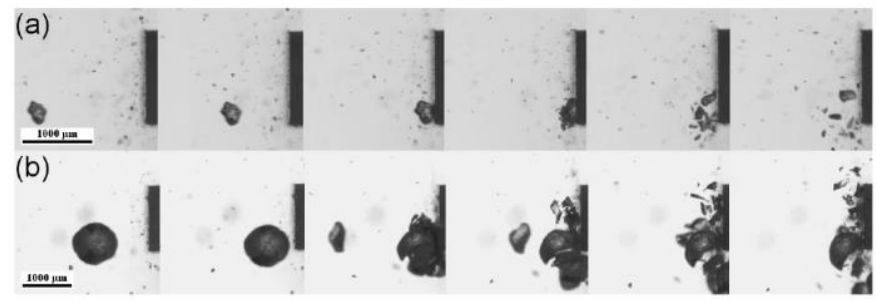

Figure 3: Impact experiment performed by AGI. Fragmentation mode impact of a non-spherical ice particle (a) and spherical ice particle (b). Time step between two successive frames is $14.9 \mu \mathrm{s}$ (Hauk et al, [11, 12])

More recently, in addition to full-engine and motor-driven-rig tests, NASA used its PSL large scale facility (Propulsion System Laboratory) for more fundamental ice-accretion studies that simulate different mixed-phase icing conditions [30,31] similar to what might occur along the core flow passage of an engine compressor. A NACA 0012 airfoil was utilised. Mixed phase conditions were generated by partially freezing the liquid-water droplets ejected from the spray bars (which is a very different process from TUBS and TSAGI's process to generate mixed phase conditions). The objective of the NASA test campaign was to investigate the influence on the accretion process of some important aerothermal and cloud parameters among which the PSL plenum humidity, the air velocity and the injected particle mean volume diameter (MVD). The ice accretions observed ranged from sharp arrow-like accretions, characteristic of ice-crystal erosion and already found in the CNRC experiments, to cases with double-horn shapes, characteristic of supercooled water accretions (see Figure 5)

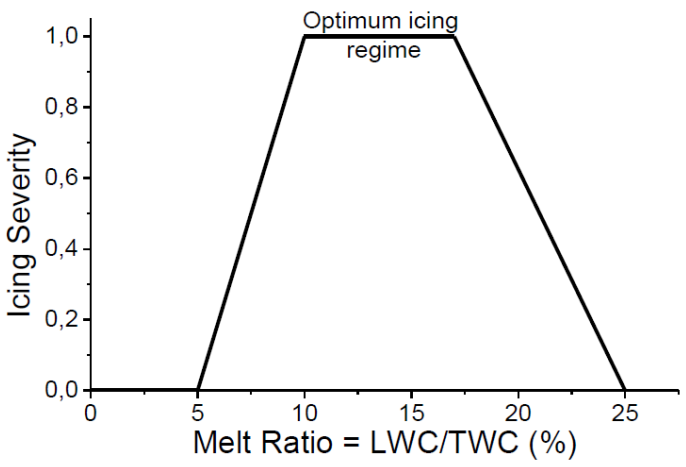

Figure 4: Icing severity versus Liquid Water Ratio as suggested by Currie et al (CNRC). At the left limit, it is inferred that not enough liquid water is present for ice particles to significantly stick to the surface. At the right limit, the amount of liquid is too high for the accreted ice-water layer to form a cohesive composite which resists to shedding or to the erosion. Insufficient cooling of the substrate surface may also play a role
All these experimental studies have led to major breakthroughs in the understanding of ICI physics, identification of the most influential parameters and development of a first set of semi-empirical models (see next subsection). However, for several physical phenomena which play a fundamental role in ICI, the available data are still not sufficient for the elaboration, calibration and validation of comprehensive models. Either they only cover a limited range of real operating conditions in terms of velocity, temperature, melt ratio, etc., or the data are not quantitative enough. Table 2 bellow provides an overview of the main gaps and limitations in the exiting database regarding particular physical phenomena.
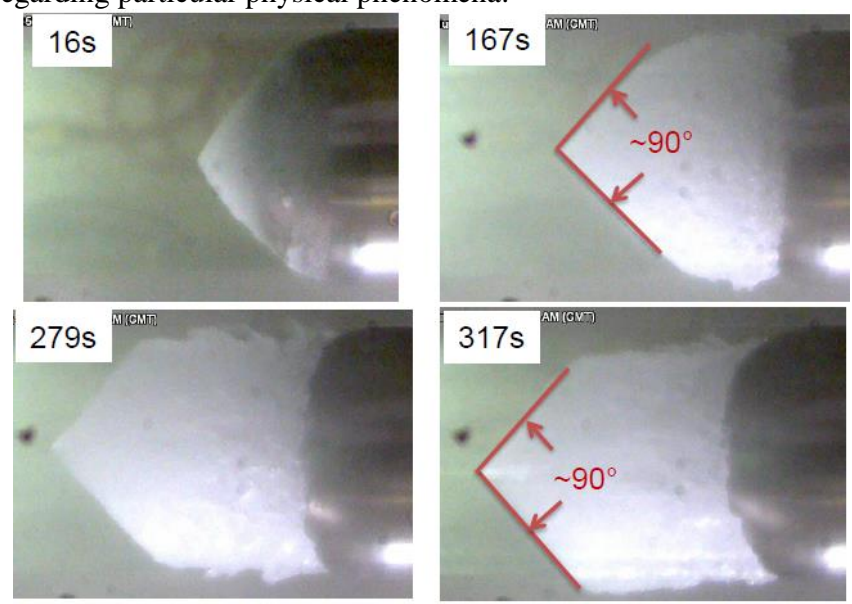

Figure 5: Typical accretion shapes after 4 different exposure times as observed in CNRC RATFac experiments. Hemispherical model of $\mathbf{4 4 . 5} \mathrm{mm}$ in diameter. Running conditions: Mach $=\mathbf{0 . 4 8}-$ TWC $=6.8 \mathrm{~g} / \mathrm{m}^{3}-$ Melt ratio $=14 \%($ Currie et al. [4] $)$

Progress beyond the state of the art. In MUSIC-haic, new experiments that go far beyond the state of the art in terms of operating range and accuracy will be performed by TUDA, AGI, TSAGI to complement the existing database and provide the modellers with the most important missing data. These experiments will study:

Impact phenomena. Two kinds of complementary experiments will be performed. TUDA will perform single ice crystal impact experiments to finally characterise ice crystal impact onto a wall. They will perform a large parametric study by varying both the wall properties (cold clean wall, heated clean wall, wetted wall, wall covered by an ice layer) and the impinging ice crystal characteristics that will be accelerated by an injection gun up to $80 \mathrm{~m} / \mathrm{s}$. The impact will be characterised in terms of deposited mass and fragment size, shape and velocity distributions. In parallel Airbus Central Research Entity will use their iCORE small icing test facility to perform similar experiments. Experimental techniques will include high-speed video microscopy, particle image velocimetry, and particle shadowgraphy. The characteristics of the injected ice particles and secondary reemitted particles (which are produced by the impact of ice crystals on solid targets) will be characterised in terms of size, velocity and melting ratio (\% melt). Airbus and TUDA experiments will also be used to better understand and characterise erosion phenomena. By exploring all types of impact conditions and by significantly increasing the impact velocity compared to the previous studies performed in HAIC, major progress will be made beyond the state of the art regarding the experimental characterisation of ice crystal impingement phenomena.

Page 5 of 10 
Accretion phenomena. Different aspects of ice crystal ice accretion will be investigated that go far beyond the original HAIC experiments and special attention will be paid to get accurate quantitative data:

- Visualisation of the ice accretion physical process on wind tunnel models that are equipped with temperature sensors and electrically heated walls. Additionally, the TSAGI airfoil model will be equipped with a water-film generation device to study ice accretion on a wetted surface. Thereby, the interaction of the large amount of ice crystals with the wetted surface including the effects of surface cooling and the liquid film destruction will be investigated.

- Characterisation of the evolution of the thickness of the accreted ice layer in time and in space for different liquid water ratio (LWR), crystal mean size, air flow temperature, humidity, flux and velocity of ice particles.

- Measurements of the final accretion shapes, temperature distribution in the solid substrate and heat fluxes.

- Estimation of the liquid water content inside the ice layer for different running conditions

MUSIC-haic will therefore provide substantial new quantitative data that are essential for improving currently available accretion models.

Table 2: Highlights of the main gaps and limitations in the exiting ICI physics database

\begin{tabular}{|c|c|}
\hline $\begin{array}{l}\text { Physical } \\
\text { phenomenon }\end{array}$ & Limitations. Missing data \\
\hline $\begin{array}{l}\text { Impact phenomena - } \\
\text { fragmentation and } \\
\text { bouncing }\end{array}$ & $\begin{array}{l}\text { HAIC quantitative experiments were limited to } \\
\text { impact onto a dry solid wall with a very limited range } \\
\text { for the impact velocity }\left(V_{\text {imp }} \leq 40 \mathrm{~m} / \mathrm{s}\right) \text {, which is far } \\
\text { from the real operating range }\left(V_{\text {imp }} \text { up to } 300 \mathrm{~m} / \mathrm{s}\right) \text {. } \\
\text { Additional results were obtained by Vargas et al [ } 33 \text {, } \\
\text { 34] for higher velocities (up to } 120 \mathrm{~m} / \mathrm{s}) \text {. Moreover } \\
\text { there exist no quantitative data for the fragmentation / } \\
\text { bouncing of partially melted ice crystals and very few } \\
\text { quantitative data for the characterisation of secondary } \\
\text { particles properties (size, shape, velocity). }\end{array}$ \\
\hline $\begin{array}{l}\text { Impact phenomena - } \\
\text { sticking efficiency }\end{array}$ & $\begin{array}{l}\text { Indirect measurement was performed by CNRC, } \\
\text { TUBS and TSAGI (based on the accretion rate or } \\
\text { total accretion mass) but with a limited accuracy } \\
\text { since it is difficult to decouple the influence of } \\
\text { sticking efficiency from the influence of other } \\
\text { parameters. No account has been made to date for the } \\
\text { properties of the impact surface, e.g. wether it is a } \\
\text { clean surface, a porous surface (granular, wet ice } \\
\text { layer) or an ice layer. }\end{array}$ \\
\hline $\begin{array}{l}\text { Impact phenomena - } \\
\text { erosion rate }\end{array}$ & $\begin{array}{l}\text { Same limitations as for sticking efficiency but with a } \\
\text { smaller experimental database (from CNRC mainly). }\end{array}$ \\
\hline $\begin{array}{l}\text { Accretion } \\
\text { phenomena - ice } \\
\text { accretion rate and ice } \\
\text { deposit shape }\end{array}$ & $\begin{array}{l}\text { Lack of detailed quantitative data with accurate } \\
\text { characterisation of the aerothermal flow and particle } \\
\text { cloud conditions, records of ice accretion shapes and } \\
\text { ice build-up rate history. }\end{array}$ \\
\hline $\begin{array}{l}\text { Accretion } \\
\text { phenomena - heat } \\
\text { and mass transfer } \\
\text { and phase change } \\
\text { inside the ice layer }\end{array}$ & $\begin{array}{l}\text { Lack of instrumented accretion experiments with } \\
\text { measurement of the temperature distribution in the } \\
\text { solid substrate and liquid water content inside the } \\
\text { accreted ice layer. }\end{array}$ \\
\hline $\begin{array}{l}\text { Shedding - shedding } \\
\text { threshold, mass and } \\
\text { velocity of shed } \\
\text { debris }\end{array}$ & $\begin{array}{l}\text { Existing database (CNRC and NASA) is very limited } \\
\text { in terms of operating conditions and mainly contains } \\
\text { qualitative data. }\end{array}$ \\
\hline
\end{tabular}

Shedding phenomena. Following research initiated in the HAIC project, different ice shedding mechanisms (affected by aerodynamic forces, by gravity, and by adhesion) will be investigated. Parametric studies will be performed, keeping some parameters constant and varying other ones until ice shedding occurs. MUSIC-haic will permit

Page 6 of 10 the creation of the first large quantitative experimental database to characterise shedding phenomena in ice crystal icing conditions.

\section{Development of a comprehensive set of models for ICI physical phenomena}

State of the art and main limitations. Within the scope of HAIC, a first set of models was developed for each of the elementary physical processes involved in ICI. These models were tested using the experimental data generated during the HAIC project and data from experiments, conducted by CNRC and NASA, before and simultaneously to HAIC. These models have not all reached the same level of maturity. This is due on the one hand to the gaps in the available data and on the other hand to the complexity of the physical phenomena. Today, one can consider that, thanks to the work previously performed $[21,22]$, the models related to the interactions between the crystals and the airflow (drag force, heat and mass transfer, melting) have reached a degree of maturity sufficient to be integrated into multidisciplinary 3D tools. No new development will be performed on these models in MUSIC-haic. However, concerning models related to impact phenomena, accretion, erosion and shedding, the situation is very different, since these models still suffer from important weaknesses.

Impact phenomena. The models proposed up to now have been calibrated and validated against a very limited database. This is particularly the case for the impact speed $(\leq 40 \mathrm{~m} / \mathrm{s}$ in HAIC experiments), the influence of the melting rate of crystals, or the influence of the properties of the impacted surface (rigid, porous, etc.) In addition, with the exception of the fragmentation threshold model which relies on a sound theoretical basis $[19,12]$, the other models (for sticking efficiency, erosion rate, secondary fragments characteristics, etc.) depend on many empirical parameters whose values have been, for the time being, fixed on the basis of data which are not representative enough of all the situations encountered in real conditions.

Accretion phenomena. Current models are based on energy and mass conservation equations for water (in solid or liquid form) in the layer of ice accreting on the wall. These models are able to predict ice shapes with an acceptable precision for the considered applications, at least in a certain range of experimental conditions. However, the heat and mass transport mechanisms inside the ice layer are taken into account in a rudimentary way. Hence, the models are not yet able to correctly reproduce experiments in hot environments with high melting rates of crystals and, therefore, poorly predict the position of the right boundary of the plateau shown in Figure 4, which is a crucial feature for estimating the severity of icing conditions. This is exemplified in Figure 6 where the model behaves very well for low and intermediate melt ratio but fail for the largest melt ratio.

Ice shedding. This is a complex phenomenon which is still very poorly understood, especially in ICI conditions. There exists almost no model of this phenomenon in the literature. However, thanks to work performed by TUDA in HAIC, a first classification of possible mechanisms has been proposed (cf. previous section). A first model was also proposed by TUDA [16] for one of the possible mechanisms (linked to the melting of the ice layer at the interface with the solid substrate). This model is able to predict the instant of shedding in the cases when the aerodynamic forces are much smaller than the ice layer adhesive and cohesive forces. 

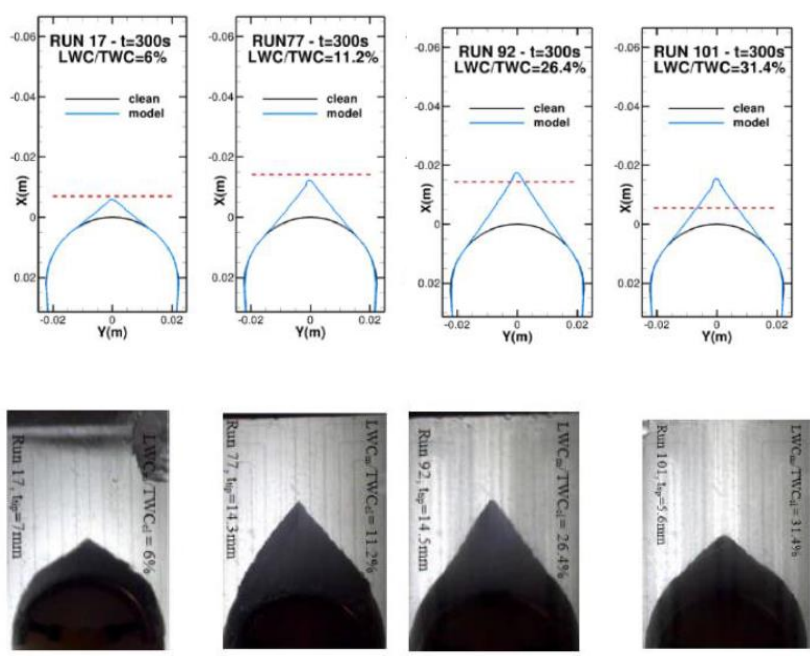

Figure 6: NRC accretion experiments [7] - Top: ONERA 2D code numerical result (blue) [32] vs. leading edge experimental ice thickness (red dashed) for $\mathbf{4}$ different values of the melt ratio

(LWC/TWC) - Bottom: side view of the experimental ice shapes.

Progress beyond the state of the art. The planned new experimental data, which will be much more abundant than those of HAIC and the continuation and generalisation of previous theoretical work, will allow the MUSIC-haic project to proceed well beyond the current state of the art.

First, as far as impact phenomena are concerned, MUSIC-haic will systematise the rigorous theoretical approach that has been applied in HAIC for the modelling of the fragmentation thresholds. This will allow the degree of empiricism of the present models to be reduced and to limit as much as possible the number of adjustable parameters. These parameters will be calibrated according to the new impact experiments that will cover most of the real encountered conditions. Inputs from other sciences like fracture dynamics, impact engineering, penetration mechanics, contact mechanics, rheology of complex materials will be exploited as required to bring new ideas and support the improvement of the existing models or the development of new ones.

Regarding accretion phenomena, MUSIC-haic will enable significant progress by modelling much more precisely the transport phenomena in the ice layer. To do so, the fact that the ice layer is not a homogeneous medium but rather a granular medium composed of a complex mixture of ice particles and liquid water will be taken into account. Figure 7 shows the different states that can be taken by such a complex granular medium. Work already performed in HAIC by TUDA [16] and the theory of granular media will be used as starting points.

Concerning shedding phenomena, MUSIC-haic will develop models to estimate the probability of an ice block to shed from a solid surface and as well the size of the largest detached fragments. These models will be expressed as functions of the ice layer liquid water content, wall surface temperature and some air flow parameters. Both qualitative and quantitative results from the tests performed by TSAGI and TUBS will be used to identify the most influential parameters and formulate semi-empirical laws. Inputs from other projects (like STORM FP7 EU project), in which shedding has been

Page 7 of 10 investigated for supercooled water icing conditions, will be used as well.

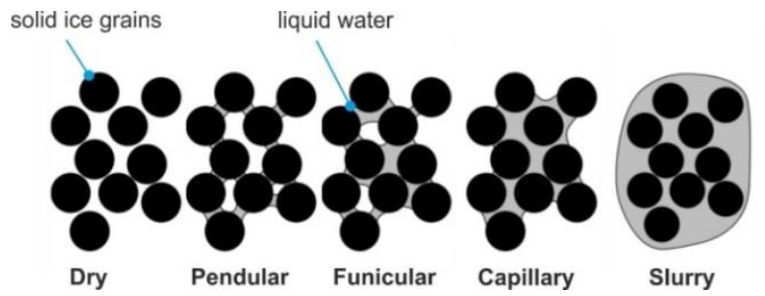

Figure 7: Different states of a wet granular media, representing the possible states of an accreted ice layer

\section{Implementation of an ICI capability in existing 3D multi- disciplinary tools}

State of the art and main limitations. At present, internationally within academia and industry, there exists no 3D numerical tool with a full ICI capability. In HAIC, the ICI models developed in the project were implemented and tested in 2D tools only (except for some trajectory and impact models which were also implemented in the ONERA Lagrangian 3D trajectory solver to perform feasibility tests). At NASA as well, up to our knowledge, a first set of models was implemented in their 2D code, LEWICE2D, but the development of a 3D ICI capability has not started yet.

In HAIC, to perform the implementation of the new models in existing 2D icing tools, the numerical methods already used for supercooled water icing simulation were extended to the case of ICI. Two main innovations were performed.

- The first innovation was the development of efficient algorithms to take into account the strong coupling between impact, accretion and heat conduction phenomena [3,16,32]. For example, the accretion and impact models need to be two-way coupled, since ice crystal sticking efficiency and erosion rate depend on the impacted ice layer properties (temperature, liquid water content) and conversely, the ice layer build-up rate depends on the impinging crystals sticking efficiency and erosion rate.

- The second important innovation was the development of new numerical methods in particle trajectory \& impact solvers to account for fragmentation phenomena and track secondary reemitted particles $[15,26]$.

Progress beyond the state of the art. As explained before, 3D multidisciplinary tools, with dedicated solvers for aerodynamics, droplet trajectories, ice accretion and heat conduction, are currently available at ONERA, CIRA, Dassault Aviation, Airbus, Rolls-Royce and General Electric but can only currently be used for supercooled liquid water icing calculations. All these tools are more or less based on the diagram displayed in Figure 2, but several couplings (mainly those involving the heat conduction and ice accretion solvers) are not yet implemented. Moreover, numerical methods to track reemitted particles after fragmentation are often not implemented.

MUSIC-haic will go well beyond the state of the art by implementing in all the partner's 3D tools a full ICI capability involving all the necessary models and their couplings. This will require not only implementing a complete set of ICI physical models for trajectory, impact, accretion and shedding, but also performing first the 
necessary improvements and adaptations to prepare their implementation. Concerning the missing couplings, MUSIC-haic will build on the experience gained in HAIC. Iterative algorithms with relaxation parameters will be used to ensure a good compromise between robustness and computational cost efficiency. This will mainly concern the coupling between the trajectory-impact solver and the accretion solver, and the coupling between the accretion solver and the solid heat conduction solver. It is worth pointing out that, for ICI simulation, a fully unsteady approach with a coupling at each time step of all the solvers cannot be applied because of the very large difference between the accretion time scale (a few minutes) and the air-flow residence time scale (one hundredth second).

For particle trajectory tracking (including interactions with walls), two approaches can be used [15]. In the Lagrangian approach, a set of particle trajectories is computed by directly solving the equations of motion. The examined set of trajectories has to be chosen large enough to be statistically representative of the entire particle cloud. In the Eulerian approach, the particle cloud is not sampled. It is modelled as a pseudo-fluid and a set of transport equations is solved for mass, momentum and energy. The Eulerian method has the advantage to be computationally less expensive than the Lagrangian one, especially if the computational domain is very large (like for probe installation and wing icing calculations), requiring a very large number of particle trajectories to be tracked to obtain reliable results. Conversely, in the Lagrangian approach, it is much easier to deal with complex physical phenomena, like fragmentation upon impact. Both approaches will be considered in MUSIC-haic.

\section{Validation tests based on real industrial configurations}

State of the art and main limitations. Up to now, both at European and international level, validation was limited to $2 \mathrm{D}$ tools and to simplified configurations (see for example Figure 6). Model predictions were compared to experimental results based on academic experiments, using generic test articles that are far from representing the whole complexity of a real industrial configuration. However, since ice crystal models are not available in 3D tools, more complex validation test cases have not been possible yet. To date, in Europe, the most realistic 3D simulations have been carried out using ONERA 3D tool, CEDRE, to simulate ice crystal trajectories in a turbofan engine [27] (Figure 8) and in the vicinity of an aircraft nose. However, these simulations were only aimed to prove the feasibility of such computations since result analysis was only qualitative.

Progress beyond the state of the art. As far as validation is concerned, MUSIC-haic will permit a real breakthrough compared to the state of the art, paving the way to making numerical tools usable by industry as design tools and acceptable means of compliance for ICI.

For aircraft engines, two kind of realistic test cases will be considered. First, the Ice Crystal Consortium (ICC) database, which contains wellinstrumented turbofan engine icing experiments will be used to define common test cases that will be performed by all the engine manufacturers involved in MUSIC-haic and by ONERA. Additional validation tests based on in-service events will also be considered by the engine manufacturers. For this second series of tests, the 3D tools will be run on real in-flight cases and will have to prove that they can reproduce the observed phenomena. The information available being limited (since in-service engines are not instrumented), the validation will be mainly qualitative.

Concerning probes, the HAIC/HIWC flight tests database will be used to assess that the new $3 \mathrm{D}$ tools are able to accurately simulate probe

Page 8 of 10 installation effects. In addition, the HAIC air-data probe icing tests performed in the DGA IWT will be used to select relevant test cases and to validate the new ICI numerical capability to predict heated probe inlet obstruction when submitted to severe icing conditions.

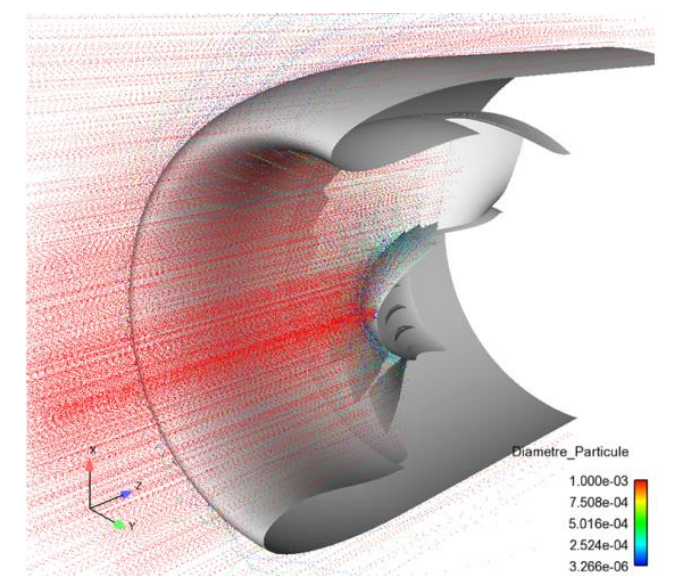

Figure 8: Ice crystal trajectories and size evolution across a generic engine (inlet+fan)

\section{Work breakdown structure of MUSIC-haic}

As shown in Figure 9 and Figure 10, the project activities are broken down into six work-packages, four being dedicated to scientific and technical activities, one to dissemination, communication and exploitation preparation, and the last one to the project management.

- WP1 will provide the missing experimental data for ICI model completion. New experiments will be performed to fill the main gaps and to provide the modellers with data necessary to formulate new models or to improve and re-calibrate existing ones.

- WP2 will complete the development of a comprehensive set of models for ICI. Building on HAIC outcomes and using data issued from WP1 and former research projects, ICI models will be progressively improved and implemented in existing 2D codes for calibration and validation purposes. At the end of WP2, a numerical benchmark will be organised to cross-check the different models and to select the best candidates for implementation in 3D numerical tools.

- WP3 will first specify the requirements for the 3D tools and will interact with WP1 regarding test matrices definition and with WP2 for models specifications. It will perform the necessary changes in the partners' existing 3D multi-disciplinary tools to prepare the implementation of the new ICI models. The downselected models issued from WP2 will then be integrated. Finally, a series of preliminary validation tests will be performed to ensure that all the tools are ready to run for WP4 applications.

- WP4 will perform the final assessment of the 3D tools developed in WP3. Relevant test cases for design and certification will be defined and run by the industrial partners with the support of tool developers. The selected test cases will be based on the existing industrial databases. Result analyses, qualitative results, main conclusions and best practices (and further needed developments if any) will be shared and agreed among all partners. 
- WP5 will undertake all the project level activities related to dissemination, communication and preparation for future exploitation.

- WP6 will be devoted to the project monitoring, administration and reporting and will ensure the technical consistency and convergence towards MUSIC-haic main objectives.

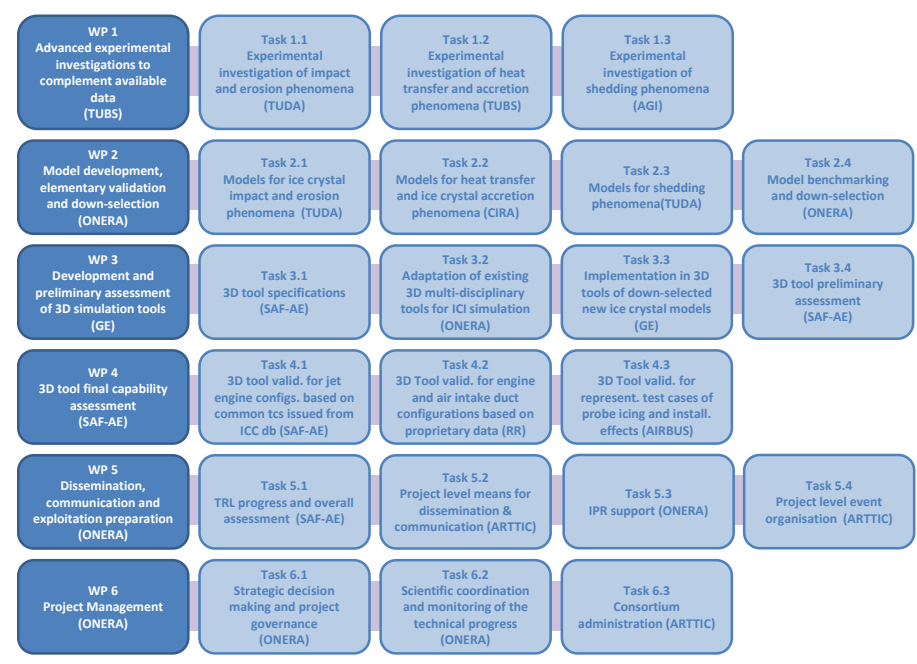

Figure 9: Project work breakdown structure

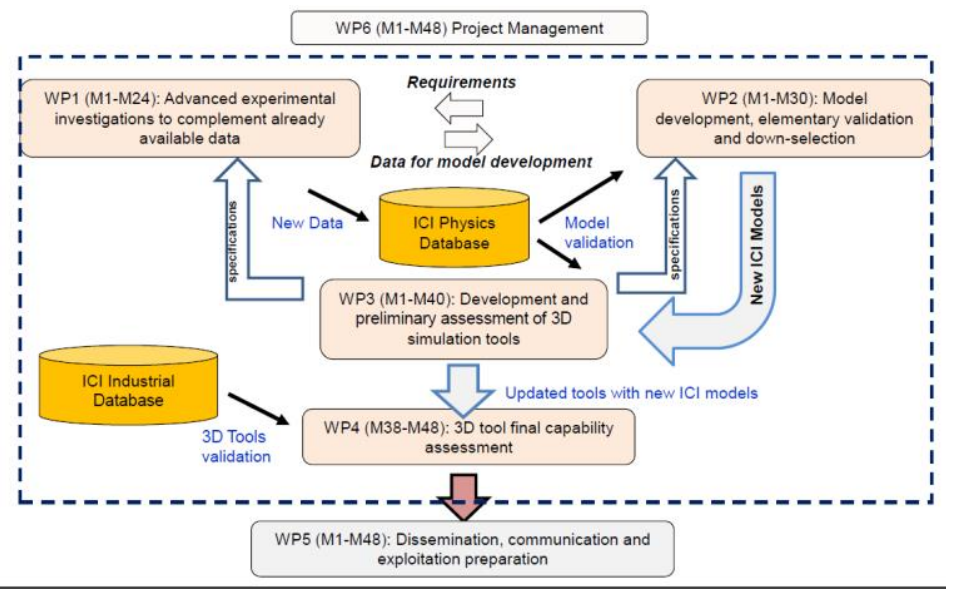

Figure 10: Interaction between the different work-packages

\section{Conclusion}

The purpose of this article was to give an overview of the project MUSIC-haic in terms of context, objectives, scientific ambition, methodology and organization. We took advantage of this opportunity to present a detailed state of the art of the knowledge and existing models in relation to the problem of ice crystal icing. We hope that benefiting from the experience of the HAIC project and bringing together the major European partners working on the subject, MUSIChaic will go far beyond the state of the art and will make major progress in terms of modeling and development of 3D numerical capabilities. The work is just beginning and we will have to take stock of the progress made in four years.

Page 9 of 10

\section{Nomenclature}

ONERA : French aerospace research center CIRA : Italian aerospace research center

TUDA : Technical University of Darmstadt

TUBS : Technical University of Braunschweig

AGI : Airbus Group Research Central Entity

TsAGI : Central Aerohydrodynamic Institute of the Russian Federation

CNRC : Canadian National Research Council

ARTTIC : Office in charge of the project administration

WP : Work-package

ICI : Ice crystal icing

\section{Reference}

[1] Technical Compendium From Meetings of the Engine Harmonization Working Group FAA Report No. DOT/FAA/AR09/13, March 2009

[2]http://www.reuters.com/article/us-airlines-boeing idUSBRE9AM03G20131123

[3] Baumert, A. , Bansmer, S. , Trontin, P. , Villedieu, P. ,2018. Experimental and numeri- cal investigations on aircraft icing at mixed phase conditions. Int. J. Heat Mass Transf. 123, 957-978

[4] Currie, T.C. , Fuleki, D.M. ,2016. Experimental results for ice crystal icing on hemi- spherical and double wedge geometries at varying Mach numbers and wet bulb temperatures. In: 8th AIAA Atmospheric and Space Environments Conference, AIAA-2016-3740

[5] Currie, T.C. , Fuleki, D.M. , Davison, C. , 2015. Simulation of ice particle melting in the NRC RATFac mixed-phase icing tunnel. In: SAE 2015 International Conference on Icing of Aircraft, Engines, and Structures, 2015-01-2107, Prague, Czech Republic

[6] Currie, T.C. , Fuleki, D.M. , Knezevici, D.C. , MacLeod, J.D. , 2013. Altitude scaling of ice crystal accretion. In: 5th AIAA Atmospheric and Space Environments Conference, AIAA-2013-2677, Orlando, USA

[7] Currie, T.C. , Fuleki, D.M., Mahallati, A. , 2014. Experimental studies of mixed-phase sticking efficiency for ice crystal accretion in jet engines. In: 6th AIAA Atmospheric and Space Environments Conference, AIAA-2014-3049

[8] Currie, T.C. , Struk, P.M. , Tsao, J.C. , Fuleki, D.M. , Knezevici, D.C. , 2012. Fundamental study of mixed-phase icing with application to ice crystal accretion in aircraft jet engines. In: 4th AIAA Atmospheric and Space Environments Conference, AIAA-2012-3035

[9] A. Flegel, M. Oliver, Preliminary results from a heavily instrument engine ice crystal icing test in a ground based altitude test facility, in: 8th AIAA Atmospheric and Space Environments Conference, AIAA 2016-3894, 2016

[10] M. Oliver, Validation ice crystal icing engine test in the propulsion system laboratory at NASA Glenn Research Center, in: 6th AIAA Atmospheric and Space Environments Conference, AIAA2014-2898, 2014

[11] Hauk, T. , 2015. Investigation of the Impact and Melting Process of Ice Particles. Technische Universität Darmstadt, Ph.D. thesis 
[12] Hauk, T. , Bonaccurso, E. , Roisman, I.V. , Tropea, C. , 2015. Ice crystal impact onto a dry solid wall. particle fragmentation. In: Proc. R. Soc. A, 471. The Royal Society

[13] Hauk, T. , Bonaccurso, E. , Villedieu, P. , Trontin, P. , 2016. Theoretical and experimental investigation of the melting process of ice particles. J. Thermophys. Heat Transfer 30 (4), 946-954

[14] Hauk, T. , Roisman, I.V. , Tropea, C. , 2014. Investigation of the melting behaviour of ice particles in an acoustic levitator. 11th AIAA/ASME Joint thermophysics and heat transfer conference, Atlanta, USA

[15] E. Norde, J.-M. Senoner, E.T.A. van der Weide, P. Trontin, H.W.M. Hoeijmakers, and P. Villedieu, Eulerian and Lagrangian Ice Crystal Trajectory Simulations in a Generic Turbofan Compressor, 2018, Journal of Propulsion and Power, DOI:10.2514/1.B36916

[16] Kintea, D.M. , Roisman, I.V. , Tropea, C. , 2016. Transport processes in a wet granular ice layer: model for ice accretion and shedding. Int. J. Heat Mass Transf. 97, 461-472

[17] Knezevici, D.C. , Fuleki, D.M. , Currie, T.C. , Galeote, B. , Chalmers, J.L.Y. , MacLeod, J.D. , 2013. Particle size effects on ice crystal accretion-part ii. In: 5th AIAA Atmo- spheric and Space Environments Conference, AIAA-2013-2676, pp. 24-27

[18] Knezevici, D.C., Fuleki, D.M. , Currie, T.C. , MacLeod, J.D. , 2012. Particle size effects on ice crystal accretion. In: 4th AIAA Atmospheric and Space Environments Conference, AIAA-2012-3039, 10, pp. 6-2012

[19] Roisman, I.V. , Tropea, C. , 2015. Impact of a crushing ice particle onto a dry solid wall. Proc. R. Soc. A 471, 20150525

[20] Struk, P.M. , Currie, T.C. , Wright, W.B. , Knezevici, D.C. , Fuleki, D.M. , Broeren, A.P. , Vargas, M. , Tsao, J.C. , 2011. Fundamental ice crystal accretion physics studies. In: SAE International Icing Conference, SAE 2011-38-0018

[21] Trontin, P., Blanchard, G., Villedieu, P. , 2016. A comprehensive numerical model for mixed-phase and glaciated icing conditions. In: 8th AIAA Atmospheric and Space Environments Conference, AIAA2016-3742.

[22] Villedieu, P., Trontin, P. , Chauvin, R. , 2014. Glaciated and mixed phase ice accretion modeling using ONERA 2D icing suite. In: 6th AIAA Atmospheric and Space Environments Conference, AIAA2014-2199, Atlanta, USA

[23] Wright, W.B. , Jorgenson, P.C.E. , Veres, J.P. , 2010. Mixed phase modeling in GLENNICE with application to engine icing. In: AIAA Atmospheric and Space Environments Conference, AIAA2010-7674

[24] Mason, J.G. , Chow, P. , Fuleki, D.M. , 2011. Understanding ice crystal accretion and shedding phenomenon in jet engines using a rig test. J. Eng. Gas Turbine Power 133 (4)

[25] Mason, J.G. , Strapp, J.W. , Chow, P. , 2006. The ice particle threat to engines in flight. 44th AIAA Aerospace Sciences Meeting, AIAA-2006-206, Reno, Nevada, USA
[26] Iuliano, E., Montreuil, E. , Norde, E. , Van der Weide, E.T.A. , Hoeijmakers, H.W.M. , 2015. Modelling of non-spherical particle evolution for ice crystals simulation with an Eulerian approach. In: SAE 2015 International Conference on Icing of Aircraft, Engines, and Structures, SAE 2015-01-2138.

[27] Gilles Aouizerate, Virgile Charton, Morgan Balland, JeanMathieu Senoner, Pierre Trontin, Claire Laurent, Ghislain Blanchard, and Philippe Villedieu. "Ice Crystals Trajectory Calculations in a Turbofan Engine", 2018 Atmospheric and Space Environments Conference, AIAA AVIATION Forum, (AIAA 2018-4130)

[28] Fabien Dezitter, Alice Grandin, Jean-Louis Brenguier, Franck Hervy, Hans Schlager, Philippe Villedieu, and Gilles Zalamansky. "HAIC - High Altitude Ice Crystals", 5th AIAA Atmospheric and Space Environments Conference, Fluid Dynamics and Co-located Conferences, (AIAA 2013-2674)

[29] E. Ayan, Serkan Özgen 2017, In-Flight Mixed Phase Ice Accretion Prediction on Finite, Wings with TAICE-3D, 7th European Conference For Aeronautics And Aerospace Sciences (Eucass)

[30] Peter M. Struk, Tadas Bartkus, Jen-Ching Tsao, Timothy Bencic, Michael King, Thomas Ratvasky and Judy Van Zante, An Initial Study of the Fundamentals of Ice Crystal Icing Physics in the NASA Propulsion Systems Laboratory, 2017 Atmospheric and Space Environments Conference, AIAA AVIATION Forum, AIAA 2017. 4242

[31] Tadas P. Bartkus, Peter M. Struk, and Jen-Ching Tsao, Evaluation of a Thermodynamic Ice-Crystal Icing Model Using Experimental Ice Accretion Data, 2018 Atmospheric and Space Environments Conference, AIAA AVIATION Forum, AIAA 20184129

[32] P. Trontin, P. Villedieu, A comprehensive accretion model for glaciated icing conditions, IJMF 108, 105-123, 2018

[33] Vargas, M., Ruggeri, C., Struk, P., Pereira, M. et al., "Ice Particle Impacts on a Flat Plate," SAE Technical Paper 2015-012099, 2015, DOI: $10.4271 / 2015-01-2099$.

[34] Mario Vargas, Charles R. Ruggeri, J. Michael Pereira, and Duane M. Revilock, "Fragment Size Distribution for Ice Particle Impacts on a Glass Plate," AIAA 2018 Atmospheric and Space Environments Conference, DOI: 10.2514/6.2018-3969.

[35] M. Widalm et al, HAIC Deliverable D63.4 - Synthesis of the TRL4 benchmark on trajectory models, Internal HAIC project Deliverable, 2015

\section{Acknowledgment}

This project has received funding from the European Union's Horizon 2020 research and innovation programme under grant agreement No 7675 